\title{
Population Structure and Biodiversity of Pectobacterium parmentieri Isolated from Potato Fields in Temperate Climate
}

Sabina Zoledowska, Agata Motyka, Dominika Zukowska, Wojciech Sledz, and Ewa Lojkowska, ${ }^{\dagger}$ Department of Biotechnology, Intercollegiate Faculty of Biotechnology, University of Gdansk and Medical University of Gdansk, 80-307 Gdansk, Poland

\begin{abstract}
Pectobacterium parmentieri (formerly Pectobacterium wasabiae) is a newly established species of pectinolytic plant-pathogenic bacteria responsible for the symptoms of soft rot and blackleg on potato. In this work, we describe biodiversity and the population structure of $P$. parmentieri strains isolated during two consecutive growing seasons from the seed potato fields in Poland. About 450 samples of diseased potato tubers, potato plants, or accompanying weeds were collected throughout the country and tested for the presence of $P$. parmentieri by molecular identification methods. We found that $P$. parmentieri strains commonly occur in almost all regions of Poland. Furthermore, these isolates constituted significant fraction of pectinolytic bacteria from seed potato fields because 16\% (2013) and 13\% (2014) of the analyzed plant samples were infected with $P$. parmentieri. Subsequently, a detailed characterization of the obtained strains was conducted basing on repetitive sequences profiling, $r e c A$-gene-based phylogeny, and

phenotypic features. By applying repetitive extragenic palindromic sequencebased polymerase chain reaction (REP-PCR), we revealed the presence of five distinct genomic profiles among $P$. parmentieri strains, with profile I being the most abundant (approximately 44\%). The performed recA gene-based phylogenetic analysis divided P. parmentieri isolates into two distinct clades, although the strains originating from different years did not group separately. Evaluation of the phenotypic traits playing crucial roles for the virulence of pectinolytic bacteria (namely, pectinase, cellulase and protease activities, and siderophore production, in addition to potato tissue maceration, swimming, and swarming motility) indicated some differences among the characterized strains. To the best of our knowledge, this is the first study that describes biodiversity and the population structure of $P$. parmentieri isolated in two growing seasons under temperate climate conditions and, hence, illustrates high heterogeneity within this species.
\end{abstract}

Pectobacterium parmentieri (formerly virulent $P$. carotovorum subsp. carotovorum or $P$. wasabiae) is a plant-pathogenic, softrotting, pectinolytic bacterium that used to be classified to the Enterobacteriaceae family (de Haan et al. 2008; Khayi et al. 2016; Nykyri et al. 2012; Waleron et al. 2013). Due to the recent comprehensive genome scale taxonomic analysis, this species has been transferred to the Pectobacteriaceae fam. nov. within the order Enterobacteriales (Adeolu et al. 2016). Microorganisms currently belonging to $P$. parmentieri underwent several taxonomic revisions during the previous years. At first, they had been incorporated into the genus Erwinia, which included Erwinia carotovora subsp. carotovora, E. carotovora subsp. atroseptica, and E. chrysanthemi among other non-pectinolytic bacterial phytopathogens. Later, Hauben et al. (1998) established the genus Pectobacterium that included four species: P. cactacidum, $P$. chrysanthemi, $P$. cypripedi, and $P$. carotovorum, the latter species consisting of the following subspecies: $P$. carotovorum subsp. atrosepticum, $P$. carotovorum subsp. betavasculorum, $P$. carotovorum subsp. carotovorum, $P$. carotovorum subsp. odoriferum, and $P$. carotovorum subsp. wasabiae. Subsequently, three subspecies of $P$. carotovorum were elevated into the species level; namely, $P$. atrosepticum, P. odoriferum, and P. wasabiae (Gardan et al. 2003; Nykyri et al. 2012).

Regarding $P$. wasabiae, it was isolated for the first time in the late 1980s from symptomatic Japanese horseradish (Goto and Matsumoto 1987) and was not considered to be a potato pathogen. Neither the occurrence of $P$. wasabiae on potato nor its presence on territory outside of Japan has been reported before 2009. In 2010, Pitman et al.

${ }^{\dagger}$ Corresponding author: E. Lojkowska, E-mail: ewa.lojkowska@biotech.ug.edu.pl

GenBank accession numbers KY889066 to KY889139 correspond to the recA gene sequences reported here.

*The $\boldsymbol{e}$-Xtra logo stands for "electronic extra" and indicates that seven supplementary figures are published online.

Accepted for publication 31 July 2017.

This article is in the public domain and not copyrightable. It may be freely reprinted with customary crediting of the source. The American Phytopathological Society, 2018.
(2010) demonstrated that $P$. wasabiae was capable of causing disease symptoms on potato plants in New Zealand. Subsequently, $P$. carotovorum subsp. carotovorum SCC3193, a model strain widely used in molecular studies (Eriksson et al. 1998; Koskinen et al. 2012), was reclassified to $P$. wasabiae SCC3193 (Nykyri et al. 2012). This event triggered further renaming of $P$. carotovorum subsp. carotovorum strains deposited in international collections as $P$. wasabiae (De Boer et al. 2012; Nabhan et al. 2012; Sławiak et al. 2013; Waleron et al. 2013). Most recent comprehensive analysis based on DNA-DNA hybridization (DDH), genome average nucleotide identity (gANI), and average nucleotide identity (ANI) values calculated in silico on $P$. wasabiae genomes resulted in reclassification of all potatooriginated $P$. wasabiae isolates into a newly established species, $P$. parmentieri (Khayi et al. 2016).

$P$. parmentieri strains are gram-negative rod-shaped necrotrophs that destroy plant tissue components through the activity of plant cell-wall-degrading enzymes (PCWDE) such as pectinases, cellulases, and proteases secreted via type I or II secretion systems (Chatterjee et al. 1995; Hugouvieux-Cotte-Pattat et al. 1996; Liu et al. 1999; Charkowski et al 2012). Pectinases play a major role in the virulence of soft-rotting pathogens because they cleave pectins, which are the branched polysaccharides present in the primary cell walls of terrestrial plants. These enzymes are divided into pectate lyases and polygalacturonases, basing on differences in their activities: pectate and pectin lyases degrade highly esterified pectins into small molecules via $\beta$-elimination mechanism, while polygalacturonases hydrolyze the $\alpha-1,4$ glycosidic bonds between galacturonic acid residues (Pickersgill et al. 1998). Other important pathogenicity factors include cellulases that hydrolyze 1,4$\beta$-D-glycosidic linkages in cellulose and hemicellulose, yielding shorter polysaccharides, oligosaccharides, or monosaccharides (Py et al. 1991). Proteases also deserve to be mentioned, because they disrupt the host plant's protoplasts via degradation of transmembrane proteins (Marits et al. 1999). In addition, an effective spread of the invading pathogen through the plant vascular system, often referred as motility of the strain, is undoubtedly essential for the development of disease symptoms (Toth et al. 2003). Moreover, efficient production of the iron-scavenging molecules provides for adequate amount of essential cofactors involved in almost all life-supporting processes (Ishimaru and Loper 1992).

High economic impact of all Pectobacterium spp. was emphasized by listing the members of this genus among the top 10 bacterial plant 
pathogens (Mansfield et al. 2012). The above-mentioned attribution was based not only on severe damage noted in potato production sector but also on a broad host range of these microorganisms. In general, Pectobacterium spp. were reported to cause soft-rotting symptoms on 16 dicot plant families in 11 orders and 11 monocot families in 6 orders (Ma et al. 2007). Particularly, P. parmentieri was described as a pathogen of a similarly broad host range as $P$. carotovorum (Pitman et al. 2010), therefore affecting such divergent vegetables and crops as potato, carrot, cabbage, maize, sugar beet, calla lily, and star of Bethlehem (Yishay et al. 2008). In addition, there were multiple reports published on the occurrence of $P$. parmentieri in various climatic zones. The presence of this pathogen was confirmed in Germany, Finland, Poland, Norway, Switzerland, The Netherlands, New Zealand, Canada, the United States, and the Republic of South Africa (De Boer et al. 2012; Dung et al. 2012; Nabhan et al. 2012; Moleleki et al. 2013; Pasanen et al. 2013; Pitman et al. 2010; Rosenzweig et al. 2016; Sławiak et al. 2013; Suárez et al. 2017; Waleron et al. 2013). More detailed analyses suggested that $P$. parmentieri strains constitute significant fraction of soft-rotting pectobacteria isolated in Poland (approximately 20\%) (Waleron et al. 2013) or Canada (16\%) (De Boer et al. 2012) whereas, in New Zealand, South Africa, or Zimbabwe, they amounted to about $5 \%$.

Despite the fact that the appearance of $P$. parmentieri was confirmed in numerous countries, no comprehensive study on the population structure and biodiversity of $P$. parmentieri strains has been conducted. Thus, the work presented here summarizes a detailed survey focusing on the monitoring and characterization of $P$. parmentieri strains isolated from seed potato plantations in Poland.

\section{Materials and Methods}

Bacterial strains, media, and culture conditions. $P$. parmentier $i$ strains isolated from seed potato plantations on the territory of Poland in 2013 and 2014 are listed in Table 1. The reference strains used in this study are included in Table 2. All investigated bacteria were grown on crystal violet pectate (CVP) (Hyman et al. 2001) or Luria broth agar (LA) media at $28^{\circ} \mathrm{C}$, unless otherwise stated. Concerning liquid cultures, bacteria were grown in lysogeny broth (LB) at $28^{\circ} \mathrm{C}$ with $120 \mathrm{rpm}$ agitation (Incur-Shaker Mini; Benchmark Scientific).

Collection of the potato plants, potato tubers, and weeds. All plant samples were collected from potato seed plantations from May to September in the growing seasons of 2013 and 2014 by the inspectors of the Regional Inspectorates of Plant Health and Seed Inspection Service in Poland. Obtained plant material included 441 samples (201 in 2013 and 240 in 2014) of blackleg-affected potato plants (117 in 2013 and 133 in 2014), tubers exhibiting the symptoms of soft rot (64 in 2013 and 79 in 2014), and a few accompanying weeds (20 in 2013 and 28 in 2014). The collected samples were placed in sealed plastic bags and sent to the Laboratory of Plant Protection and Biotechnology of the Intercollegiate Faculty of Biotechnology, University of Gdansk and Medical University of Gdansk.

Isolation and identification of $\boldsymbol{P}$. parmentieri strains. Approximately $1 \mathrm{~g}$ of plant tissue was homogenized in Bioreba extraction bag (Bioreba), while flooded with $10 \mathrm{ml}$ of phosphate-buffered saline $(\mathrm{pH}$ 7.2). Aliquots of $100 \mu \mathrm{l}$ from $10^{-5}$ and $10^{-6}$ serial dilutions of the homogenates were plated on CVP medium. Later, cavity-forming colonies were picked up and repeatedly grown first on CVP and then on LA medium in order to obtain axenic cultures. Afterward, cell lysates prepared by freezing and thawing of dense bacterial suspensions were subjected to multiplex polymerase chain reaction (PCR) (Potrykus et al. 2014b). All lysates that gave specific amplicons with the ExpccR and ExpccF primers (Kang et al. 2003) were used for subsequent single $\mathrm{PCR}$ with $\mathrm{PhF}$ and $\mathrm{PhR}$ primers, which are specific for the identification of $P$. parmentieri (De Boer et al. 2012). All strains designated as $P$. parmentieri were frozen in $40 \%$ glycerol and stored for further use at $-80^{\circ} \mathrm{C}$.

Genomic characterization of $\boldsymbol{P}$. parmentieri strains. Bacterial genomic DNA was isolated by utilizing the Genomic Mini AX Bacteria Kit (A\&A Biotechnology) and diluted to the final concentration of $10 \mathrm{ng} \mu \mathrm{l}^{-1}$.

Repetitive sequence-based PCR analysis. Genomic profiles of $P$. parmentieri strains were obtained by implementing the repetitive sequence-based (REP) PCR, as described by Versalovic et al. (1991). Preliminary studies were performed with the use of BOX, ERIC, and REP primers and, for further analysis, REP 1 R-I and REP 2-I primers were selected. The resulting amplicons were separated by electrophoresis in $1 \%$ agarose (Basica) gel in $0.5 \times$ Tris-borate-EDTA buffer at $50 \mathrm{~V}$ for $4 \mathrm{~h}$, visualized, and documented with the Gel Doc imaging system (Bio Rad Laboratories Inc.) supported by the Quantity One Software (Bio Rad Laboratories Inc.). The obtained fingerprints were analyzed by Bionumerics 6.5 software (Applied Maths). All of the reference strains used for comparison purposes are listed in Table 2. recA gene-based phylogenetic analysis. Amplification of the 730-bp fragment of the recA gene was carried out by following the previously described protocol (Waleron et al. 2002) and involved 78 $P$. parmentieri strains collected during both years of study. The generated amplicons were sequenced from both ends by Genomed Ltd. and were edited manually afterward with the use of CLC Main Workbench 6.5 software (Qiagen). The 590-bp recA gene fragment was selected for further studies involving the construction of a recA gene-based phylogenetic tree (neighbor-joining algorithm with the Jukes-Cantor nucleotide distance measure) by implementing CLC MainWorkbench 6.5. Moreover, the recA gene sequences of $P$. parmentieri SCC3193, isolated in Finland; five strains isolated in Poland in 1996 (IFB5317, IFB5320, IFB5325, IFB5332, and IFB5553); and each one from the United States (WPP163), Canada (CFIA1002), Scotland (SCRI103), and France $\left(\mathrm{CFBP} 8475^{\mathrm{T}}\right.$ ), in addition to $P$. wasabiae (CFBP3304) from Japan, were downloaded from the GenBank database and included in the conducted analysis. The bootstrap value was set on the level of 100 replicates. Dickeya solani IFB0099 was used as an outgroup.

Phenotypic analysis of $\boldsymbol{P}$. parmentieri strains. Overnight bacterial cultures in LB were centrifuged for $10 \mathrm{~min}$ at $6,500 \mathrm{rpm}$ and washed twice in Ringer's solution to remove the residuals of the medium. The prepared bacterial suspensions were adjusted to an optical density at $600 \mathrm{~nm}$ of 0.1 (approximately $10^{8} \mathrm{CFU} \mathrm{m} l^{-1}$ ) and used for inoculation of the plate assays listed below, with a volume of $2 \mu \mathrm{l}$. All of the tests were incubated at $28^{\circ} \mathrm{C}$ for $48 \mathrm{~h}$, unless otherwise stated. The experiments were carried out in three biological repetitions, including four technical replicates each.

Pectinase activity was tested on M63Y PGA (polygalacturonate) plates (Reverchon et al. 1986). After $48 \mathrm{~h}$ of incubation, this medium was stained with an aqueous solution of $10 \%$ copper acetate. Degradation of PGA resulted in the appearance of whitish halo zones around bacterial colonies, which were measured in order to assess the total pectinase activity.

Cellulase activity was analyzed on M63 medium supplemented with glycerol at $2 \mathrm{~g} \mathrm{liter}^{-1}$ and carboxymethylcellulose at $10 \mathrm{~g} \mathrm{liter}^{-1}$ (Wood 1980). After $48 \mathrm{~h}$ of incubation, the plates were flooded with Congo Red solution at $10 \mathrm{mg} \mathrm{ml}^{-1}$ for $10 \mathrm{~min}$ and subsequently washed with $1 \mathrm{M} \mathrm{NaCl}$ for $5 \mathrm{~min}$. The halo diameter appearing around the colonies indicated the activity of cellulase and was subsequently measured.

Protease activity was evaluated on medium containing skim milk at $12.5 \mathrm{~g} \mathrm{liter}^{-1}$ (Ji et al. 1987). Diameters of the clear halos around the colonies reflecting the activity of proteases were measured after $24 \mathrm{~h}$ of incubation.

Siderophore production capacity was determined on chrome azurol S-agar plates (Schwyn and Neilands 1987). Diameters of the orange halo zones around the colonies corresponding to siderophore production rate were measured after $72 \mathrm{~h}$ of incubation.

Swarming motility was assessed by inoculating nutrient agar (NA) plates solidified with $0.6 \%$ agar (Harshey 2003). Diameters of the colonies were measured after $24 \mathrm{~h}$ of incubation.

Swimming motility was assessed by inoculating NA plates solidified with $0.3 \%$ agar (Harshey 2003). Diameters of the colonies were measured after $24 \mathrm{~h}$ of incubation.

Potato slice maceration assay was performed on 'Lord' potato tubers (average size $=60$ to $70 \mathrm{~mm}$ ). Tubers were washed under running water and sterilized with $10 \%$ commercially available bleach for $20 \mathrm{~min}$. Later, the tubers were thoroughly washed in water and dried in the laminar flow cabinet. Subsequently, all of the tubers were aseptically cut crosswise into 10 -mm-thick slices, in which two holes ( 5 by $5 \mathrm{~mm}$ ) per slice were drilled. The potato slices were placed in plastic boxes 
( 200 by 320 by $75 \mathrm{~mm}$ ) covered with a layer of moistened Whatman filter paper. Afterward, each hole in every potato slice was inoculated with $50 \mu$ l of bacterial suspension $\left(10^{8} \mathrm{CFU} \mathrm{ml}^{-1}\right.$, prepared as described above). Incubation lasted $48 \mathrm{~h}$ at $28^{\circ} \mathrm{C}$. After this time, the rotten tissue diameters were measured. As a negative control, $0.85 \% \mathrm{NaCl}$ was used. The experiment was repeated twice, involving eight technical replicates.

Statistical analysis. Statistical significance of differences observed in phenotypic assays (i.e. enzymatic activities, siderophore production, motility, and ability to macerate potato tissue) was analyzed by R, version 3.3.2 (2016-10-31) (R Core Team 2014). Levene's test was applied for testing the equality of variances and the Shapiro-Wilk's test was implemented for evaluating normality of the data. The differences among group means were tested by the analysis of variance, followed by Tukey's honestly significance test. $P$ value $<0.05$ was used.

Statistical analysis on $\mathrm{rec} A$ gene sequences was conducted in order to quantitatively evaluate the genetic biodiversity between strains isolated from the same plant in each year according to the previously described protocol (Mengoni and Bazzicalupo 2002). To measure variance among the selected isolates, 650-bp fragments of $P$. parmentieri recA gene sequences were used. For this purpose, analysis of molecular variance (AMOVA) by Arlequin 3.5 (Excoffier et al. 2005) was applied.

\section{Results}

$P$. parmentieri strains commonly occur on potato seed plantations in Poland. Pectobacterium spp. were isolated from 230 plant samples (101 and 129 in years 2013 and 2014, respectively). $P$. parmentieri strains were detected in approximately $16 \%$ of all tested plant samples in 2013 whereas, in 2014, they amounted to $13 \%$. The total number of isolated strains was similar between the years of study, equaling 47 in 2013 and 38 in 2014. The $P$. parmentieri isolates originated from blackleg-affected potato stems (24 in 2013 and 29 in 2014), potato tubers with the symptoms of soft rot (17 in 2013

Table 1. Pectobacterium parmentieri strains isolated from potato fields in Poland

\begin{tabular}{|c|c|c|c|c|c|c|c|}
\hline \multirow[b]{2}{*}{ Number } & \multirow[b]{2}{*}{ Strain $^{\mathbf{b}}$} & \multirow[b]{2}{*}{ Host plant } & \multirow[b]{2}{*}{ Year $^{\mathrm{c}}$} & \multirow[b]{2}{*}{ REPd } & \multicolumn{3}{|c|}{ SNP in $r e c A$ gene sequence from ATG codon ${ }^{a}$} \\
\hline & & & & & SNP1, 138 bp, GA & SNP2, 540 bp, TA & SNP3, 642 bp, CT \\
\hline 1 & IFB5400 & Potato stem & 2013 & II & $\ldots$ & $\ldots$ & $\ldots$ \\
\hline 2 & IFB5491 & Potato tuber & 2013 & I & $\ldots$ & $\ldots$ & $\ldots$ \\
\hline 3 & IFB5493 & Potato tuber & 2013 & II & + & + & + \\
\hline 4 & IFB5404 & Potato stem & 2013 & III & NE & $\mathrm{NE}$ & $\mathrm{NE}$ \\
\hline 5 & IFB5497e & Potato stem & 2013 & II & $\mathrm{NE}$ & $\mathrm{NE}$ & NE \\
\hline 6 & IFB5498 & Potato stem & 2013 & II & $\ldots$ & $\ldots$ & $\ldots$ \\
\hline 7 & IFB5405 & Potato stem & 2013 & I & $\ldots$ & $\ldots$ & $\ldots$ \\
\hline 8 & IFB5406 & Potato tuber & 2013 & I & $\ldots$ & $\ldots$ & $\ldots$ \\
\hline 9 & IFB5407 & Potato stem & 2013 & I & $\ldots$ & $\ldots$ & $\ldots$ \\
\hline 10 & IFB5408 & Potato stem & 2013 & I & $\ldots$ & + & $\ldots$ \\
\hline 11 & IFB5409 & Potato stem & 2013 & III & + & + & $\ldots$ \\
\hline 12 & IFB5410 & Potato stem & 2013 & I & $\ldots$ & + & $\ldots$ \\
\hline 13 & IFB5411 & Potato stem & 2013 & I & $\ldots$ & + & $\ldots$ \\
\hline 14 & IFB5412 & Potato stem & 2013 & I & $\ldots$ & $\ldots$ & $\ldots$ \\
\hline 15 & IFB5413 & Potato stem & 2013 & I & $\ldots$ & $\ldots$ & $\ldots$ \\
\hline 16 & IFB5414 & Weed & 2013 & IV & $\ldots$ & + & $\ldots$ \\
\hline 17 & IFB5415 & Potato stem & 2013 & I & $\ldots$ & $\ldots$ & $\ldots$ \\
\hline 18 & IFB5416 & Potato stem & 2013 & I & $\ldots$ & + & + \\
\hline 19 & IFB5417 & Soil & 2013 & II & + & + & + \\
\hline 20 & IFB5418 & Potato stem & 2013 & III & $\ldots$ & + & $\ldots$ \\
\hline 21 & IFB5419 & Weed & 2013 & II & + & + & + \\
\hline 22 & IFB5420 & Potato stem & 2013 & II & $\ldots$ & $\ldots$ & $\ldots$ \\
\hline 23 & IFB5421 & Potato tuber & 2013 & IV & $\ldots$ & $\ldots$ & $\ldots$ \\
\hline 24 & IFB5422 & Potato tuber & 2013 & IV & $\ldots$ & $\ldots$ & $\ldots$ \\
\hline 25 & IFB5423 & Potato stem & 2013 & III & $\ldots$ & $\ldots$ & $\ldots$ \\
\hline 26 & IFB5424 & Potato stem & 2013 & I & $\ldots$ & $\ldots$ & $\ldots$ \\
\hline 27 & IFB5425 & Potato stem & 2013 & III & $\ldots$ & $\ldots$ & $\ldots$ \\
\hline 28 & IFB5426 & Potato stem & 2013 & IV & $\ldots$ & $\ldots$ & $\ldots$ \\
\hline 29 & IFB5427 & Weed & 2013 & I & $\ldots$ & + & $\ldots$ \\
\hline 30 & IFB5428 & Weed & 2013 & IV & $\ldots$ & $\ldots$ & $\ldots$ \\
\hline 31 & IFB5429 & Weed & 2013 & I & $\ldots$ & + & $\ldots$ \\
\hline 32 & IFB5430 & Potato tuber & 2013 & II & $\ldots$ & $\ldots$ & $\ldots$ \\
\hline 33 & IFB5431 & Potato tuber & 2013 & II & $\ldots$ & $\ldots$ & $\ldots$ \\
\hline 34 & IFB5432 & Potato tuber & 2013 & III & + & + & + \\
\hline 35 & IFB5433 & Potato tuber & 2013 & III & + & + & + \\
\hline 36 & IFB5434 & Potato tuber & 2013 & III & + & + & + \\
\hline 37 & IFB5435 & Potato tuber & 2013 & I & $\ldots$ & + & $\ldots$ \\
\hline 38 & IFB5436 & Potato tuber & 2013 & I & $\ldots$ & + & $\ldots$ \\
\hline 39 & IFB5437 & Potato tuber & 2013 & I & $\ldots$ & + & $\ldots$ \\
\hline 40 & IFB5441 & Potato tuber & 2013 & II & + & + & + \\
\hline
\end{tabular}

a The recA sequence of $P$. parmentieri SCC3193 was used as a reference; + indicates the presence of single-nucleotide polymorphism (SNP) at a given position, $\mathrm{NE}=$ not established due to lack of amplification, and NT $=$ not tested.

${ }^{\mathrm{b}}$ IFB $=$ the collection of bacterial plant pathogens at the Intercollegiate Faculty of Biotechnology University of Gdansk and Medical University of Gdansk, Gdansk, Poland.

${ }^{c}$ Year of isolation

${ }^{\mathrm{d}}$ Repetitive sequence-based (REP) profile.

e Strains were described previously by Dees et al. (2017). 
and 4 in 2014), asymptomatic weeds (5 in 2013 and 5 in 2014), and soil (1 in 2013). In this work, out of $85 P$. parmentieri isolates, we focused on 78 (40 from 2013 and 38 from 2014; Table 1). In 16 cases (3 in 2013 and 13 in 2014), more than one P. parmentieri strain of diverse genotypic feature was isolated from a certain plant sample (Table 3).

Genomic characterization of $\boldsymbol{P}$. parmentieri strains. By comparison of various REP-PCR fingerprinting methods incorporating either BOX, REP, or ERIC primers, we defined REP profiling as the most useful tool for further grouping of $P$. parmentieri strains. The obtained REP genomic profiles included 8 to 10 bands of 750 to 3,000-bp in size. Five distinct profiles (numbers I to V) were distinguished among the tested $P$. parmentieri strains by utilizing Bionumerics 6.5 (Applied Maths) (Fig. 1). REP profile I was the most abundant, because it was observed among approximately $44 \%$ of the strains isolated in both 2013 and 2014 (Fig. 2). This pattern was also characteristic for the reference strain $P$. parmentieri SCC3193 isolated in
Finland. The incidence of profiles II and III was similar among the strains originating from the consecutive years. In contrast, REP profile IV was observed only among strains isolated in 2013, while REP profile V exclusively among the ones from 2014 (Fig. 2). As shown for $P$. wasabiae CFBP3304, all of the tested $P$. wasabiae strains isolated from Japanese horseradish exhibited a distinct REP profile. Interestingly, $P$. parmentieri strains isolated from the same potato plant indicated different REP profiles in several cases (Table 3).

All of the isolated $P$. parmentieri strains grouped into two separate clades on the basis of phylogenetic analysis performed on a 590-bp recA gene fragment (Fig. 3). Regardless of the year of isolation, $P$. parmentieri from 2013 and 2014 could be found in both clades, although the majority of the strains originating from 2014 constituted clade 1 (30 of 38), whereas the ones from 2013 separated almost equally into clades 1 and 2 . Remarkably, $P$. parmentieri CFBP $8475^{\mathrm{T}}$ type strain isolated in France was present in clade 2 . In addition, the reference strain $P$. parmentieri SCC3193 grouped within clade 1, together

Table 1. (continued from previous page)

\begin{tabular}{|c|c|c|c|c|c|c|c|}
\hline \multirow[b]{2}{*}{ Number } & \multirow[b]{2}{*}{ Strain $^{\mathbf{b}}$} & \multirow[b]{2}{*}{ Host plant } & \multirow[b]{2}{*}{ Year $^{\mathrm{c}}$} & \multirow[b]{2}{*}{ REPd } & \multicolumn{3}{|c|}{ SNP in $r e c A$ gene sequence from ATG codon ${ }^{a}$} \\
\hline & & & & & SNP1, 138 bp, GA & SNP2, 540 bp, TA & SNP3, 642 bp, CT \\
\hline 41 & IFB5442 & Potato tuber & 2013 & I & $\ldots$ & + & $\ldots$ \\
\hline 42 & IFB5443 & Potato tuber & 2013 & I & + & + & + \\
\hline 43 & IFB5500e & Potato stem & 2013 & III & NT & NT & NT \\
\hline 44 & IFB5501 & Potato stem & 2013 & I & NT & NT & NT \\
\hline 45 & IFB5507e & Potato stem & 2013 & II & NT & NT & NT \\
\hline 46 & IFB5511 & Potato stem & 2013 & II & NT & NT & NT \\
\hline 47 & IFB5513 $^{\mathrm{e}}$ & Potato tuber & 2013 & I & NT & NT & NT \\
\hline 48 & IFB5597 & Potato stem & 2014 & I & $\ldots$ & $\ldots$ & $\ldots$ \\
\hline 49 & IFB5598 & Potato stem & 2014 & I & $\ldots$ & $\ldots$ & $\ldots$ \\
\hline 50 & IFB5599 & Weed & 2014 & I & $\ldots$ & $\ldots$ & $\ldots$ \\
\hline 51 & IFB5600 & Potato stem & 2014 & I & $\ldots$ & $\ldots$ & $\ldots$ \\
\hline 52 & IFB5601 & Potato stem & 2014 & II & $\ldots$ & $\ldots$ & $\ldots$ \\
\hline 53 & IFB5602 & Weed & 2014 & I & $\ldots$ & $\ldots$ & $\ldots$ \\
\hline 54 & IFB5603 & Potato stem & 2014 & II & $\ldots$ & $\ldots$ & $\ldots$ \\
\hline 55 & IFB5604 & Potato stem & 2014 & $\mathrm{~V}$ & $\ldots$ & $\ldots$ & $\ldots$ \\
\hline 56 & IFB5605 & Potato stem & 2014 & I & $\ldots$ & + & $\ldots$ \\
\hline 57 & IFB5606 & Potato stem & 2014 & II & $\ldots$ & $\ldots$ & $\ldots$ \\
\hline 58 & IFB5607 & Potato stem & 2014 & I & $\ldots$ & $\ldots$ & $\ldots$ \\
\hline 59 & IFB5608 & Potato stem & 2014 & I & $\ldots$ & $\ldots$ & $\ldots$ \\
\hline 60 & IFB5609 & Potato stem & 2014 & I & $\ldots$ & $\ldots$ & $\ldots$ \\
\hline 61 & IFB5610 & Potato stem & 2014 & I & $\ldots$ & $\ldots$ & $\ldots$ \\
\hline 62 & IFB5611 & Potato stem & 2014 & $\mathrm{~V}$ & $\mathrm{NE}$ & $\mathrm{NE}$ & $\mathrm{NE}$ \\
\hline 63 & IFB5612 & Potato stem & 2014 & II & $\ldots$ & $\ldots$ & $\ldots$ \\
\hline 64 & IFB5613 & Potato stem & 2014 & I & $\ldots$ & $\ldots$ & $\ldots$ \\
\hline 65 & IFB5614 & Potato stem & 2014 & I & $\ldots$ & $\ldots$ & $\ldots$ \\
\hline 66 & IFB5616 & Potato stem & 2014 & $\mathrm{~V}$ & $\ldots$ & $\ldots$ & $\ldots$ \\
\hline 67 & IFB5617 & Potato stem & 2014 & II & $\ldots$ & $\ldots$ & $\ldots$ \\
\hline 68 & IFB5618 & Potato stem & 2014 & I & $\ldots$ & $\ldots$ & $\ldots$ \\
\hline 69 & IFB5619 & Potato stem & 2014 & III & $\ldots$ & $\ldots$ & $\ldots$ \\
\hline 70 & IFB5620 & Potato stem & 2014 & $\mathrm{~V}$ & $\ldots$ & $\ldots$ & $\ldots$ \\
\hline 71 & IFB5621 & Potato tuber & 2014 & III & $\ldots$ & $\ldots$ & $\ldots$ \\
\hline 72 & IFB5622 & Potato tuber & 2014 & I & $\ldots$ & + & $\ldots$ \\
\hline 73 & IFB5623 & Potato stem & 2014 & II & + & + & + \\
\hline 74 & IFB5624 & Potato stem & 2014 & III & $\ldots$ & $\ldots$ & $\ldots$ \\
\hline 75 & IFB5625 & Potato tuber & 2014 & II & $\ldots$ & $\ldots$ & $\ldots$ \\
\hline 76 & IFB5626 & Potato tuber & 2014 & I & $\ldots$ & + & $\ldots$ \\
\hline 77 & IFB5627 & Weed & 2014 & $\mathrm{~V}$ & $\ldots$ & + & $\ldots$ \\
\hline 78 & IFB5628 & Weed & 2014 & III & $\ldots$ & $\ldots$ & $\ldots$ \\
\hline 79 & IFB5629 & Potato stem & 2014 & III & $\ldots$ & $\ldots$ & $\ldots$ \\
\hline 80 & IFB5630 & Weed & 2014 & II & $\ldots$ & $\ldots$ & $\ldots$ \\
\hline 81 & IFB5631 & Potato stem & 2014 & III & $\ldots$ & $\ldots$ & $\ldots$ \\
\hline 82 & IFB5632 & Potato stem & 2014 & III & $\ldots$ & $\ldots$ & $\ldots$ \\
\hline 83 & IFB5633 & Potato stem & 2014 & III & $\ldots$ & $\ldots$ & $\ldots$ \\
\hline 84 & IFB5634 & Potato stem & 2014 & I & $\ldots$ & + & $\ldots$ \\
\hline 85 & IFB5635 & Potato stem & 2014 & I & $\ldots$ & + & $\ldots$ \\
\hline
\end{tabular}


with $P$. parmentieri from the United States, Canada, and Scotland, and several strains isolated in Poland in 1996 (Fig. 3).

Regarding single-nucleotide polymorphisms (SNP), we were able to distinguish three SNP regions in the analyzed 590-bp fragment of the recA gene: namely, G-A transversion at the 138-bp position, counting from the beginning of ATG codon (observed in $12.8 \%$ of the tested strains); T-A transition at 540-bp (35.9\% cases); and C-T transversion at 642 -bp (characteristic for $11.54 \%$ of $P$. parmentieri isolates). The above mentioned 540-bp T-A transition was more common among strains isolated in $2013(52.5 \%$ of the analyzed strains) than those originating from 2014 (18.4\% events). Moreover, G-A transversion at 138-bp and C-T transversion at 642-bp were described more frequently among the strains from the 2013 population $(22.50 \%)$ than from $2014(2.63 \%)$ (Table 1).

In 8 of 17 cases, we obtained bacterial isolates varying in any genotypic feature in other words, different REP profile or SNP in recA gene sequence (Table 3 ) from the same plant material therefore, biodiversity among these strains was determined by measuring molecular diversity indexes. Within the 650-bp recA gene fragment analyzed, we determined three transitions and two transversions among strains isolated from the same plant in year 2013, whereas four transitions and five transversions were noted for the strains from 2014 sharing the same plant origin. This observation pointed to higher genomic variability among the latter isolates.

Phenotypic characterization of $\boldsymbol{P}$. parmentieri strains. Crucial virulence determinants of soft-rotting pectinolytic bacteria, including pectinase, cellulase, and protease activities; siderophore production; and ability to macerate potato tissue, swim, and swarm, were evaluated for all of the investigated $P$. parmentieri strains (Supplementary Figs. S1, S2, S3, S4, S5, S6, and S7). Mean values of each phenotypic trait determined for the $P$. parmentieri populations from 2013 and 2014 were calculated and compared with the results collected for $P$. parmentieri SCC3193, $P$. wasabiae CFBP3304, P. carotovorum subsp. carotovorum IPO200, P. atrosepticum LMG2386, and D. solani IFB0099 (Fig. 4).

Interestingly, we observed higher variability in the pectinase and cellulase activities among distinct $P$. parmentieri strains from 2014 than the ones from 2013. Notably, 13 of 38 strains isolated in 2014 did not exhibit any cellulolytic activity. In the case of three P. parmentieri isolates (IFB5611, IFB5632, and IFB5635), lack of cellulolytic and low pectinolytic activities highly correlated with the impaired ability to macerate potato tissue. Ten other strains that indicated lack of cellulolytic activity did not show lower virulence than the rest of the $P$. parmentieri isolates.

The average pectinase and cellulase activities between the 2013 and $2014 P$. parmentieri populations were not significantly different (Fig. 4). It is worth noticing that $P$. parmentieri SCC 3193 showed significantly lower pectinase activity than the strains isolated in Poland. However, in terms of cellulases activity, the observed differences were statistically insignificant. Focusing on D. solani IFB0099, this strain exhibited higher activities of both pectinases and cellulases than the Pectobacterium spp. strains (Fig. 4A and B) and also the highest virulence (Fig. 5).

Individual $P$. parmentieri strains varied in protease activity, with no dependence on the year of isolation. Furthermore, the mean protease activity of the population from 2013 was significantly higher than the one calculated for isolates from 2014 (Fig. 4C). Interestingly, P. parmentieri SCC 3193 showed no protease activity. In general, all of the analyzed $P$. parmentieri strains showed significantly lower mean protease activities than $P$. wasabiae CFBP3304, $P$. carotovorum subsp. carotovorum IPO200, and D. solani IFB0099 (Fig. 4C). In only a few cases ( $P$. atrosepticum LMG2386 and P. parmentieri IFB5629 and IFB5611), lack of the protease activity could have been correlated with the decreased maceration capacity on potato.

Regarding the capacity of $P$. parmentieri to efficiently chelate iron ions, we observed significant differences in siderophore production rate between the individual strains from 2013 and 2014. In general, strains from 2013 showed significantly lower siderophore production than the strains isolated in 2014. Corresponding to what was observed for cellulase and pectinase activities, highly virulent $D$. solani IFB0099 showed the highest production of siderophores, whereas the reference strains $P$. parmentieri, $P$. wasabiae, and $P$. atrosepticum revealed no siderophore production (Fig. 4D). In the case of only two reference strains ( $P$. atrosepticum LMG2386 and $P$. wasabiae CFBP3304), a lower siderophore production rate could not have been correlated with the decreased potato maceration capacity.

Concerning swimming and swarming abilities, individual $P$. parmentieri isolates from 2014 were more motile than those isolated in 2013. In addition, isolates from 2014 exhibited higher variation in swimming motility than the strains originating from the preceding year. Additionally, significantly higher motility was noted for the entire 2014 population than for the one from 2013 (Fig. 4E and F).

Table 2. References of pectinolytic bacteria used in this study

\begin{tabular}{|c|c|c|c|c|c|c|}
\hline Species, number & Strain $^{\mathbf{a}}$ & Host, location & Yearb & REPc & GenBank $r e c A$ accession & Reference \\
\hline \multicolumn{7}{|c|}{ Pectobacterium parmentieri } \\
\hline 1 & CFBP8475 RNS08.42.1A & Potato & 2008 & NT & NZ_CP015749.1 & Khayi et al. 2016 \\
\hline 2 & CFIA1002 & Potato stem, Canada & 2007 & NT & NZ_JENG01000009.1 & De Boer et al. 2012 \\
\hline 3 & WPP163 & Potato, United States & 2008 & NT & СР001790.1 & Ma et al. 2007 \\
\hline 4 & SCRI103 & Potato tuber, Scotland & 1977 & NT & AY264795.1 & Waleron et al. 2002 \\
\hline 5 & SCC3193 & Potato, Finland & 1980s & I & NC_017845 & Nykyri et al. 2012 \\
\hline 6 & IFB5317 & Potato stem, Poland & 1996 & NT & КС584996.1 & Waleron et al. 2013 \\
\hline 7 & IFB5320 & Potato stem, Poland & 1996 & NT & КС584997.1 & Waleron et al. 2013 \\
\hline 8 & IFB5325 & Potato stem, Poland & 1996 & NT & КС584998.1 & Waleron et al. 2013 \\
\hline 9 & IFB5332 & Potato stem, Poland & 1996 & NT & KC585000.1 & Waleron et al. 2013 \\
\hline 10 & IFB5553 & Potato stem, Poland & 1996 & NT & AY217080.1 & Waleron et al. 2013 \\
\hline \multicolumn{7}{|l|}{ P. wasabiae } \\
\hline 11 & CFBP3304 & Horseradish Japan & 1985 & VI & NZ_CP015750 & $\begin{array}{l}\text { Goto and Matsumoto } \\
1987\end{array}$ \\
\hline \multicolumn{7}{|c|}{ P. carotovorum subsp. carotovorum } \\
\hline 12 & IPO200 & Potato, The Netherlands & 1974 & VII & NT & PRI \\
\hline \multicolumn{7}{|l|}{ P. atrosepticum } \\
\hline 13 & LMG2386 & Potato stem & 1957 & NT & NT & BCCM \\
\hline \multicolumn{7}{|l|}{ Dickeya solani } \\
\hline 14 & IFB0099 & Potato stem, Poland & 2005 & NT & NT & Slawiak et al. 2009 \\
\hline
\end{tabular}


Although the highest swarming ability of all of the investigated strains was attributed to $P$. parmentieri SCC3193, it had lower swimming motility than the isolates obtained in from 2014 (Fig. 4E and F). However, the noted higher swimming or swarming motility of the strains could not have been correlated with increased virulence on potato, at least in this experimental setup.

Potato maceration abilities, which can be linked with the virulence of soft-rotting phytopathogens, indicated that distinct $P$. parmentieri isolates from 2013 degraded potato tissue to the similar extent, whereas the strains from 2014 significantly differed from one another in this capacity. Although the strains from 2013 exhibited higher maceration ability from the isolates originating from 2014, the observed variation was not statistically significant. In spite of showing higher maceration than the $P$. parmentieri isolates from 2014, $P$. parmentieri SCC 3193 showed lower potato maceration capacity than the strains from 2013. Notably, D. solani IFB0099 revealed the highest potato maceration ability under the implemented conditions (Fig. 5).

\section{Discussion}

In this study, a 2-year survey on the occurrence of $P$. parmentieri on seed potato plantations in Poland is presented. We have demonstrated the ubiquitous presence of this pathogen in a temperate climate on the territory located mostly within the North European Plain. This statement is supported by the fact that the $P$. parmentieri strains were detected in 16\% (2013) and 13\% (2014) of all analyzed plant samples. Even though the appearance of bacteria currently classified to this taxon has been broadly documented in European countries since the 1990s (Dees et al. 2017; Nabhan et al. 2012; Pasanen et al. 2013; Waleron et al. 2013), there was no study focusing on genotypic and phenotypic biodiversity of the country-scale populations of $P$. parmentieri originating from the consecutive growing seasons. Thus far, scientific interest was attributed mainly to molecular or biochemical identification methods (De Boer et al. 2012; Waleron et al. 2002), reclassification of isolates deposited in international collections (Nykyri et al. 2012; Waleron et al. 2013), their phylogenetic relatedness (Pasanen et al. 2013; Pitman et al. 2010; Waleron et al. 2013), and their ability to cause disease symptoms (Pasanen et al. 2013). The research presented here provides extensive description of genomic features and virulence determinants defined for $78 P$. parmentieri isolates of divergent plant and geographical origin and, as a consequence, contributes significantly to broadening knowledge about this newly established plant pathogen.

Concerning genotypic characterization of $P$. parmentieri isolates, five various REP genomic profiles were assigned to the tested isolates. The implemented REP fingerprinting method was proven to be distinctive enough to reveal subtle differences among individual $P$. parmentieri strains from the territory of Poland. Interestingly, REP profile I characterized the highest fraction of $P$. parmentieri strains analyzed in both years. Because the same REP pattern I was also attributed to $P$. parmentieri SCC 3193 , a common origin of the strains differing in isolation time (approximately 30 years) and from either Finland or Poland might be suspected. In addition, implementation of REP-PCR allowed us to establish a specific profile for $P$. wasabiae, different from the profiles assigned to $P$. parmentieri.

Among other genotyping methods applied for characterization of Pectobacterium spp. thus far, PCR restriction fragment length polymorphism (RFLP) (Moleleki et al. 2013; Waleron et al. 2002), random amplified polymorphic DNA PCR (Maki-Valkama and Karjalainen 1994), multilocus sequence analysis (MLSA), and fluorescent amplified fragment length polymorphism (fAFLP) (Pitman et al. 2010) should be listed. For instance, Waleron et al. (2002, 2013) implemented PCR-RFLP on a recA 730-bp gene fragment to describe the genotypic relatedness between 19 different species of the former genus Erwinia. In the growing season 1996-97, 600 strains of $P$. carotovorum (43\% of all pectinolytic isolates) were obtained from soft rot- or blackleg-affected potato plants from the territory of Poland. Taking into account that 14 of 50 P. carotovorum strains were assigned with recA PCR-RFLP profile 3 , typical for the current $P$. parmentieri strains, it can be concluded that this plant pathogen was frequently isolated from potato fields in Poland even 20 years ago (Waleron et al. 2002, 2013). However, the recA PCRRFLP showed only limited discriminant abilities for investigation of within-species variation because one single profile was reported for bacteria now belonging to $P$. parmentieri. A similar approach, undertaken by Moleleki et al. (2013), amplified the 16S-23S intergenic transcribed spacer (ITS) region of atypical Pectobacterium spp. originating from South Africa and subsequently cut the resulting DNA fragments with two restriction enzymes. The applied procedure enabled differentiation of $P$. parmentieri isolates from other Pectobacterium spp., with the exception of $P$. wasabiae, although it did not seem distinctive enough for evaluation of within-species variation. In addition, focusing on only one gene might not reveal diversification that could have been disclosed from a genome-wide repetitive sequences analysis. Also, utilization by Moleleki et al. (2013) and Waleron et al. (2013) of either two or four separate restriction enzyme digestions increases the required time and cost of the whole analysis.

To the best of our knowledge, the study presented here is the first to describe, in detail, the phylogenetic relatedness between numerous individual $P$. parmentieri strains. We observed two distinct clades within this species on the basis of a 590-bp fragment of the highly conserved housekeeping $r e c A$ gene. In the reported grouping, the majority of the $P$. parmentieri isolates $(n=21)$ from 2013 constituted clade 2, together with only few $(n=7)$ strains from 2014 and the $P$. parmentieri type strain CFBP $8475^{\mathrm{T}}$. The other clade (clade 1)

Table 3. Characteristics of the Pectobacterium parmentieri originating from the same plant

\begin{tabular}{|c|c|c|c|c|}
\hline $\begin{array}{l}\text { Year, plant } \\
\text { sample }\end{array}$ & Strain & Host plant & REP$^{a}$ & $\begin{array}{l}\text { SNP in recA } \\
\text { sequence }^{\mathrm{b}}\end{array}$ \\
\hline \multicolumn{5}{|l|}{2013} \\
\hline \multirow[t]{3}{*}{1} & IFB5427 & Weed & I & No difference \\
\hline & IFB5429 & Weed & I & No difference \\
\hline & IFB5428 & Weed & V & No difference \\
\hline \multirow[t]{2}{*}{2} & IFB5430 & Potato tuber & II & No difference \\
\hline & IFB5431 & Potato tuber & II & No difference \\
\hline \multirow[t]{3}{*}{3} & IFB5432 & Potato tuber & III & 138 bp, G-A \\
\hline & IFB5433 & Potato tuber & III & $642 \mathrm{bp}, \mathrm{C}-\mathrm{T}$ \\
\hline & IFB5434 & Potato tuber & III & $642 \mathrm{bp}, \mathrm{C}-\mathrm{T}$ \\
\hline \multicolumn{5}{|l|}{2014} \\
\hline \multirow[t]{2}{*}{1} & IFB5599 & Weed & I & No difference \\
\hline & IFB5602 & Weed & I & No difference \\
\hline \multirow[t]{2}{*}{2} & IFB5601 & Potato stem & II & No difference \\
\hline & IFB5603 & Potato stem & II & No difference \\
\hline \multirow[t]{2}{*}{3} & IFB5604 & Potato stem & V & 540 bp, T-A \\
\hline & IFB5605 & Potato stem & I & $540 \mathrm{bp}, \mathrm{T}-\mathrm{A}$ \\
\hline \multirow[t]{2}{*}{4} & IFB5606 & Potato stem & II & 540 bp, T-A \\
\hline & IFB5607 & Potato stem & I & $540 \mathrm{bp}, \mathrm{T}-\mathrm{A}$ \\
\hline \multirow[t]{2}{*}{5} & IFB5608 & Potato stem & I & 540 bp, T-A \\
\hline & IFB5609 & Potato stem & I & $540 \mathrm{bp}, \mathrm{T}-\mathrm{A}$ \\
\hline \multirow[t]{2}{*}{6} & IFB5612 & Potato stem & II & No difference \\
\hline & IFB5614 & Potato stem & I & No difference \\
\hline \multirow[t]{2}{*}{7} & IFB5616 & Potato stem & V & No difference \\
\hline & IFB5617 & Potato stem & II & No difference \\
\hline \multirow[t]{2}{*}{8} & IFB5625 & Potato tuber & II & No difference \\
\hline & IFB5621 & Potato tuber & III & No difference \\
\hline \multirow[t]{2}{*}{9} & IFB5622 & Potato tuber & I & No difference \\
\hline & IFB5626 & Potato tuber & I & No difference \\
\hline \multirow[t]{2}{*}{10} & IFB5624 & Potato stem & III & No difference \\
\hline & IFB5629 & Potato stem & III & No difference \\
\hline \multirow[t]{2}{*}{11} & IFB5628 & Weed & III & No difference \\
\hline & IFB5630 & Weed & II & No difference \\
\hline \multirow[t]{2}{*}{12} & IFB5631 & Potato stem & III & No difference \\
\hline & IFB5633 & Potato stem & III & No difference \\
\hline \multirow[t]{2}{*}{13} & IFB5634 & Potato stem & I & No difference \\
\hline & IFB5635 & Potato stem & I & No difference \\
\hline
\end{tabular}

${ }^{a}$ Repetitive sequence-based (REP) profile.

${ }^{\mathrm{b}} \mathrm{SNP}=$ single-nucleotide polymorphisms 
was formed by over a dozen strains obtained in $2013(n=16)$, most of the $P$. parmentieri isolates from $2014(n=30), 5$ strains isolated in Poland in 1996, in addition to several reference strains from international collections that had been obtained from such various countries as Finland (SCC3193), Canada (CFIA1002), Scotland (SCRI103), or the United States (WPP163).

Our results support the diversification described by Khayi et al. (2016), owing to the fact that both the genome-to-genome distance and DDH estimations between the $P$. parmentieri $\mathrm{CFBP} 8475^{\mathrm{T}}$ and other $P$. parmentieri isolates (SCC3193, CFIA1002, and WPP163) pointed to similar genomic distance between the strains separated into two recA-based clades. Additionally, the in silico calculated gANI and the distance tree of concatenated sequences of $r p o D$, gyrB, recA, rpoS, fusA, dnaX, gyrA, purA, dnaN, gapA, and rplB indicated the highest genomic distance between the $P$. parmentieri $\mathrm{CFBP} 8475^{\mathrm{T}}$ and the other investigated $P$. parmentieri strains (namely, SCC3193 and WPP163). Apart from the work of Khayi et al. (2016), P. parmentieri had not been differentiated from $P$. wasabiae strains in any of the previously conducted studies. Nevertheless, the observations made by De Boer et al. (2012) and Waleron et al. (2013) clearly support the division, proposed here, of $P$. parmentieri strains into two discrete clades. In detail, P. parmentieri strains isolated in Poland in 1996 clustered together with the reference strains SCC3193, SCRI103, and
WPP163 outside subcluster IA of the maximum-likelihood-based phylogenetic tree constructed on 730-bp recA gene fragment (Waleron et al. 2013). Moreover, the heavily branched neighbor-joining cladogram on the proA gene sequence and the concatenated maximum-likelihood tree on both $m d h$ and gapA partial gene sequences constructed by De Boer et al. (2012) and Moleleki et al. (2013), respectively, imply even more complex phylogenetic relationships within this taxonomic group and account for possible further rearrangements within $P$. parmentieri species.

In the present study, we decided to focus on individual SNP as one of the measures for genotypic variation within the $r e c A$ gene fragment, studied in detail, of $P$. parmentieri. We described three SNP at positions of 138,540 , and 642-bp observed in the $22.5,52.5$, and $22.5 \%$ fractions, respectively, of the $P$. parmentieri population from 2013. Regarding the $P$. parmentieri population from 2014, the above-listed SNP were noted for 2.6, 18.4, and $2.6 \%$ of the investigated isolates. Both the unequal distribution of the isolates from 2013 and 2014 within the distinct clades of the constructed phylogenetic tree and the above-shown observation on polymorphic sites point to assumption that the $P$. parmentieri population in 2013 was genetically more heterogeneous than the one from 2014.

As is commonly known, biodiversity is the biological insurance against loss or poor performance of a species and provides for specific

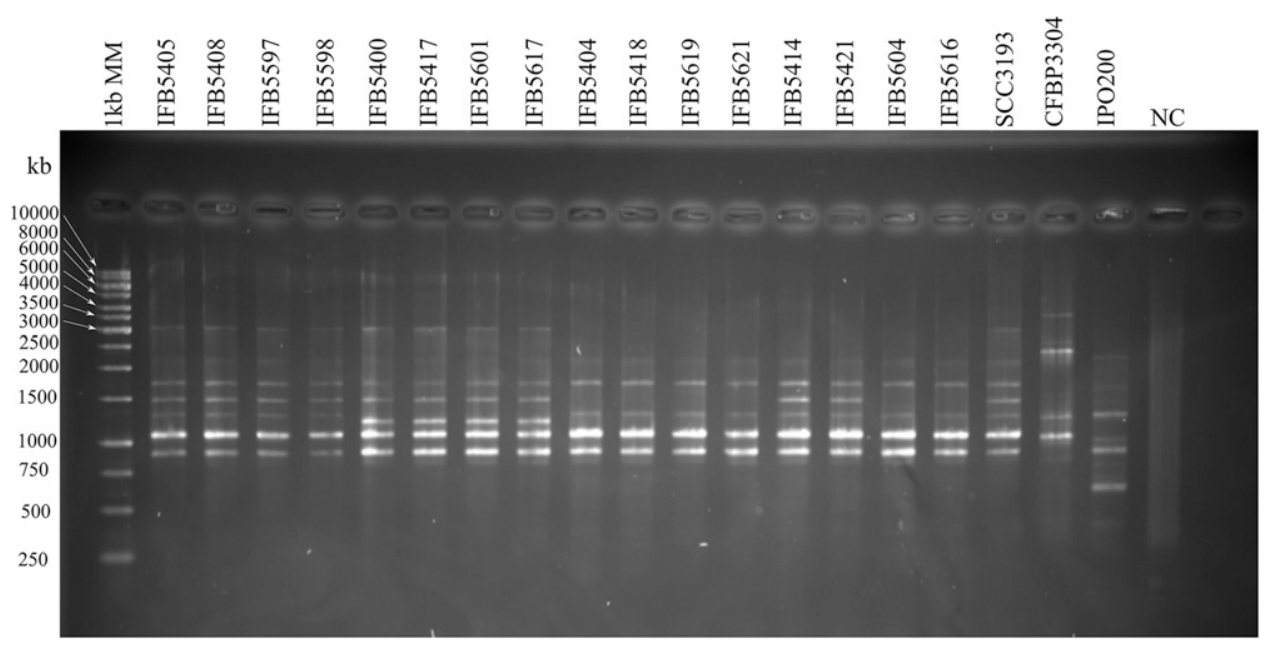

Fig. 1. Repetitive sequence-based (REP) profile analysis of Pectobacterium spp. strains. Lanes 1 to 4 , REP profile I (IFB5405, IFB5408, IFB5597, and IFB5598); lanes 5 to 8, REP profile II (IFB5400, IFB5417, IFB5601, and IFB5617); lanes 9 to 12, REP profile III (IFB5404, IFB5418, IFB5619, and IFB5621); lanes 13 and 14, REP profile IV (IFB5414 and IFB5421); lanes 15 and 16, REP profile V (IFB5604 and IFB5616); lane 17, Pectobacterium parmentieri SCC3193; lane 18, P. wasabiae CFBP3304; lane 19, P. carotovorum subsp. carotovorum IPO200; lane 20, negative control (NC). MM = GeneRuler 1-kb DNA Ladder (Thermo Scientific).
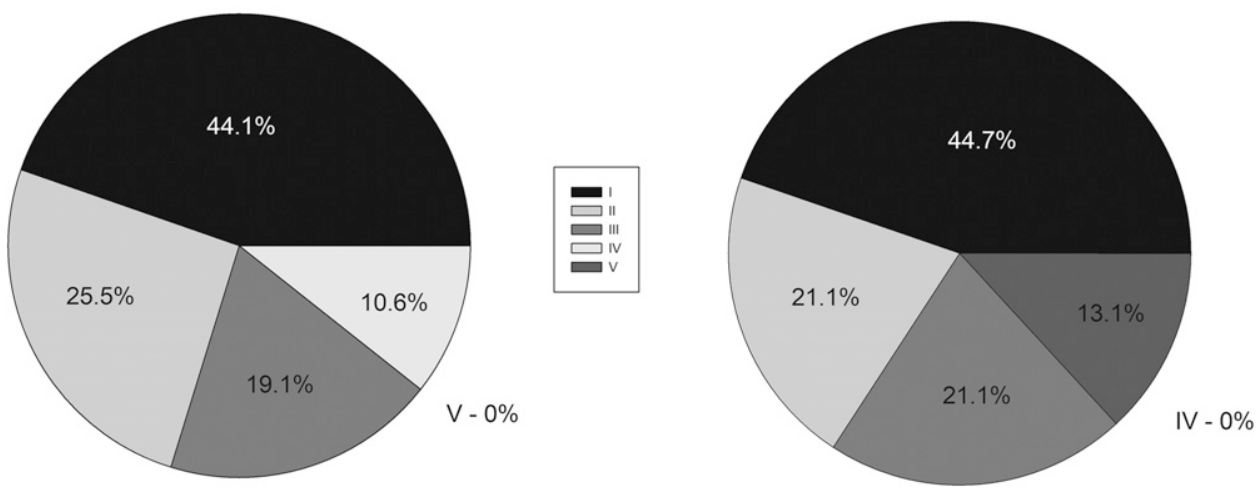

Fig. 2. Comparison of the distribution of specific repetitive sequence-based (REP) profiles among Pectobacterium parmentieri populations from 2013 and 2014. 
advantages under any environmental fluctuations (e.g. temperature) (Naeem and Li 1997). Wang et al. (2016) have tested the impact of coldness and warmth on species richness in a large-scale field experiment and confirmed that changes in temperature affect variation among bacterial communities. Taking into account these statements, we analyzed the agrometeorological data collected in Poland in 2013 and 2014 (Central Statistical Office of Poland 2016). In winter, significantly lower air temperature ( $P$ approximately $4.2 \mathrm{e}-13$ ) occurred in 2012-13 than in 2013-14, with the means equaling $-1.8 \pm 1.3^{\circ} \mathrm{C}$ and $+2.3 \pm 1.1^{\circ} \mathrm{C}$, respectively. Also in $2012-13$, higher precipitation of $39.8 \pm 5.5 \mathrm{~mm}$ was noted ( $P$ approximately $2.5 \mathrm{e}-08$ ) in comparison with $27.1 \pm 5.4 \mathrm{~mm}$ recorded in 2013-14. The above-presented data might be one of the reasons for higher variability observed among the strains collected in vegetation season of 2013. Average temperatures collected for the summer seasons in 2013 and 2014 were also juxtaposed; however, no statistically significant differences were noted $(P<0.05)$.

In order to evaluate biodiversity among $P$. parmentieri isolates from the same plant samples, we used AMOVA analysis. It revealed that strains originating from 2014 exhibited more transitions and transversions in the recA gene than the strains isolated in 2013. In general, transversions occurred more frequently than transitions. Also, Yap et al. (2004) reported unexpected variability among $P$. carotovorum (including P. parmentieri at that time) isolates from single host obtained from one region and season. Factors other than the potato host plant have been suggested as the driving force of evolution within this species.

Because the investigated $P$. parmentieri strains exhibit high genotypic variation, the phenotypic divergence reported here is not unexpected. A more intriguing trend was previously observed for D. solani strains, among which only one REP, BOX, and ERIC profile and $100 \%$ homology of housekeeping genes sequences were described thus far (Golanowska et al. 2016). Despite their homogeneity on the genotypic level, these isolates significantly vary in their abilities to produce PCWDE or siderophores or in motility (Golanowska et al. 2016; Potrykus et al. 2014a, 2016). In terms of pectinase production, all of the analyzed $P$. parmentieri isolates exhibited relatively high activity of these enzymes, except for two strains from 2014 (IFB5635 and IFB5611). Waleron et al. (2013) reported that the $P$. wasabiae isolated from horseradish showed significantly lower pectinase activities than the $P$. parmentieri strains obtained from potato, which is consistent with the presented results. Additionally, regarding all PCWDE tested, the $P$. parmentieri isolates from 2014 exhibited greater diversification in the enzyme production rates than the strains obtained in 2013. Importantly, there were few P. parmentieri strains (mostly from 2014) that did not demonstrate any proteolytic or cellulolytic capacities. Previously, Dees et al. (2017), while comparing the annual populations of pectinolytic bacteria in Poland and in Norway, demonstrated that a $P$. parmentieri strain (IFB5511) was incapable of cellulose degradation. Although the capacity to produce siderophores is frequently encountered among plant-pathogenic bacteria (Leong and Neilands 1982) and was exhibited by all strains of $P$. parmentieri isolated in Poland, there were three reference strains $P$. parmentieri SCC3193, $P$. wasabiae CFBP3304, and P. atrospeticum LMG2386 deprived of this trait. Regarding motility, $P$. parmentieri isolates from 2014 were significantly more motile in the case of either swimming or swarming than the isolates from 2013 or the investigated reference strains (except for $P$. parmentieri SCC3193).

Most of all, every tested $P$. parmentieri isolate was capable of macerating potato tissue. High maceration capacity of the current $P$. parmentieri strains was reported earlier by Waleron et al. (2013). It is worth noting that $P$. wasabiae CFBP3304 exhibited the lowest virulence. These outcomes support the fact that $P$. parmentieri used to be named highly virulent $P$. carotovorum subsp. carotovorum (de Haan et al. 2008). However, Dees et al. (2017) observed lower maceration ability of the tested $P$. parmentieri strains in comparison with other species of pectinolytic bacteria. Generated disagreement could be attributed to varying experimental setups: inoculation of potato slices versus whole potato tubers and aerobic versus anaerobic conditions. The anaerobic conditions established by Dees et al. (2017) might be more favorable for other pectinolytic species ( $P$. carotovorum subsp. carotovorum or D. solani) than for P. parmentieri; however, further research in this field is required.

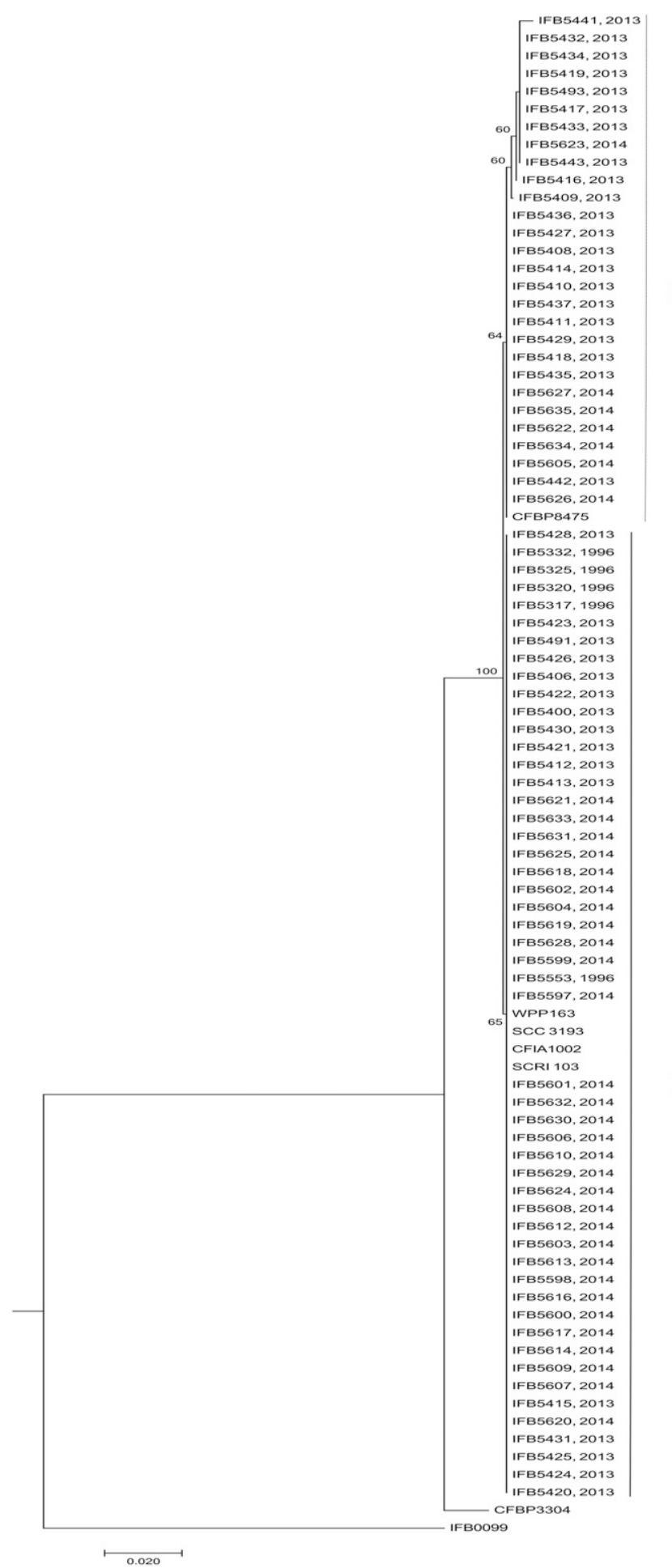

Fig. 3. Phylogenetic analysis based on recA gene sequences of Pectobacterium parmentieri strains isolated in Poland. Reference strains included in this study but also originating from other European countries are as follows: P. parmentieri isolated in the United States (WPP163), Canada (CFIA1002), Scotland (SCRI103), and France (RNS08.42.1A); P. wasabiae CFBP3304 (Japan); and six strains of $P$. parmentieri in 1996 on the territory of Poland (IFB5317, IFB5320, IFB5325, IFB5332, and IFB5553). Dickeya solani IFB0099 (Poland) was used as an outgroup. The tree was generated with a neighbor-joining algorithm with the Jukes-Cantor nucleotide distance measure CLC MainWorkbench 6.5 software (Qiagen). Bootstrap was set on the level of 100 replicates. IFB = the collection of the Intercollegiate Faculty of Biotechnology University of Gdansk and Medical University of Gdansk, Gdansk, Poland. 
Pectinase activity

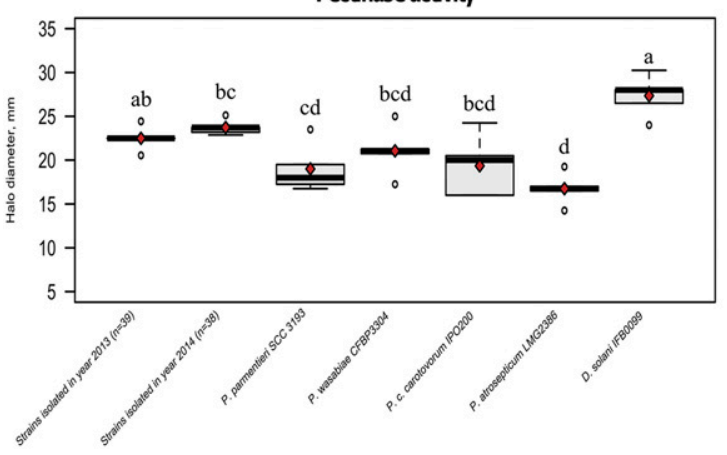

Protease activity

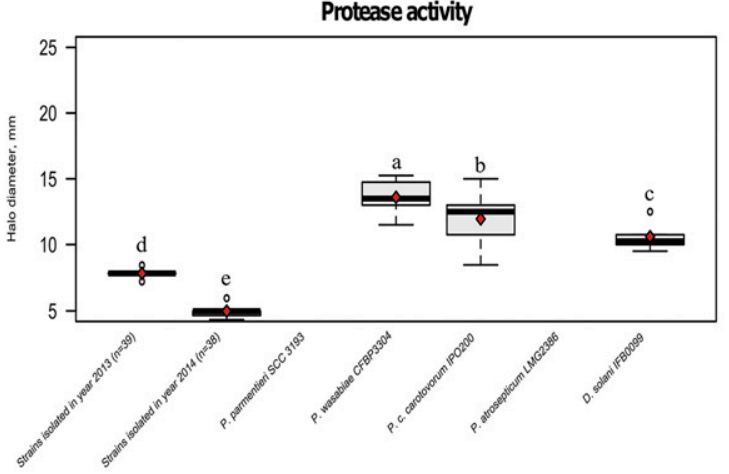

Swimming motility

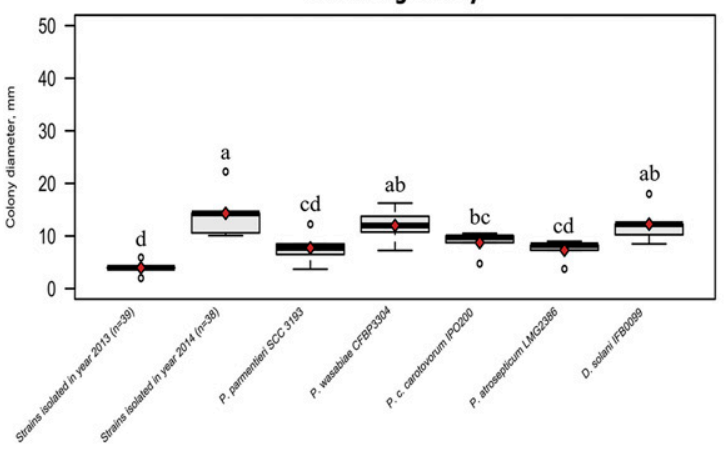

Cellulase activity

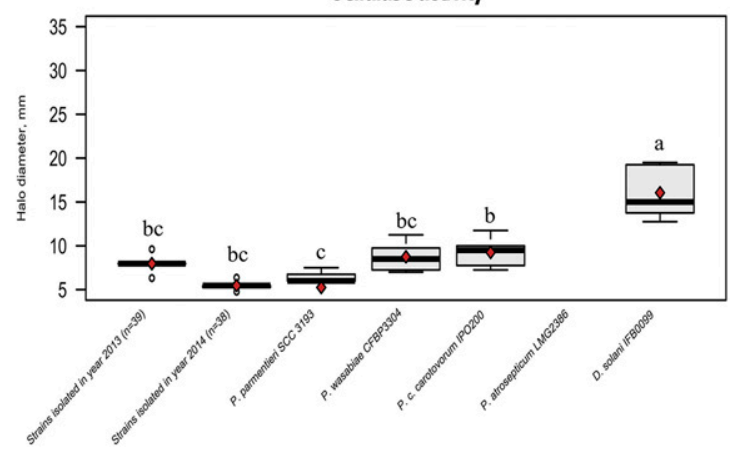

Siderophore activity

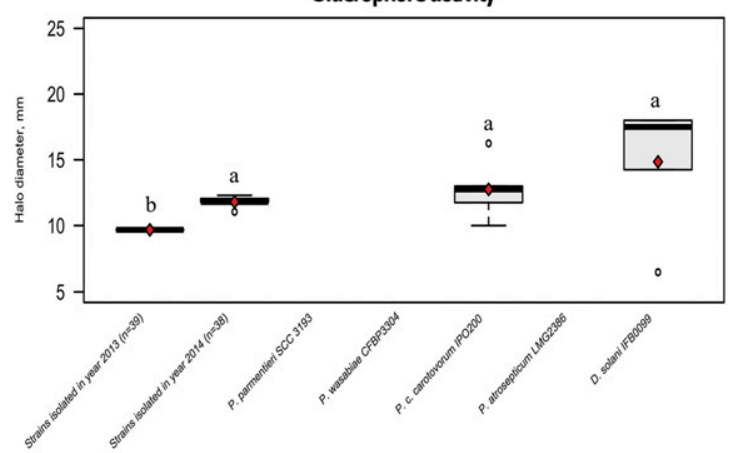

Swarming motility

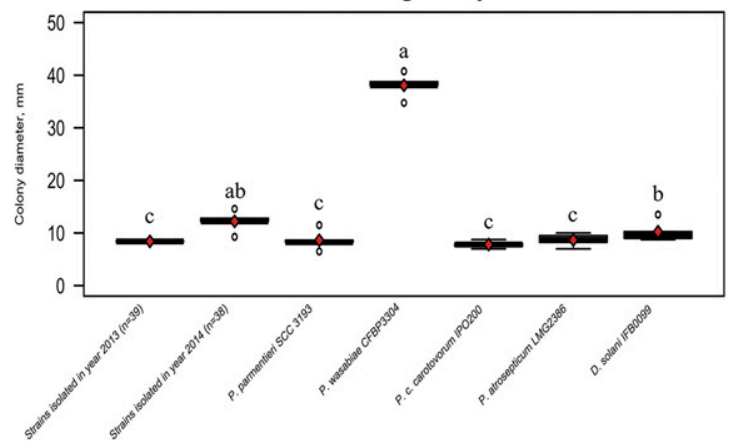

Fig. 4. Phenotypic characteristics of Pectobacterium parmentieri strains isolated in Poland. Main traits connected with $P$. parmentieri virulence have been compared: pectinase cellulase, protease activities, siderophore production, swimming and swarming ability. The top and bottom lines of the boxplot refer to upper and lower quartiles, respectively. The ends of the whiskers reach minimum and maximum values. The dark diamond represents the mean and the black bar depicts the median. Outliners are marked by circles.

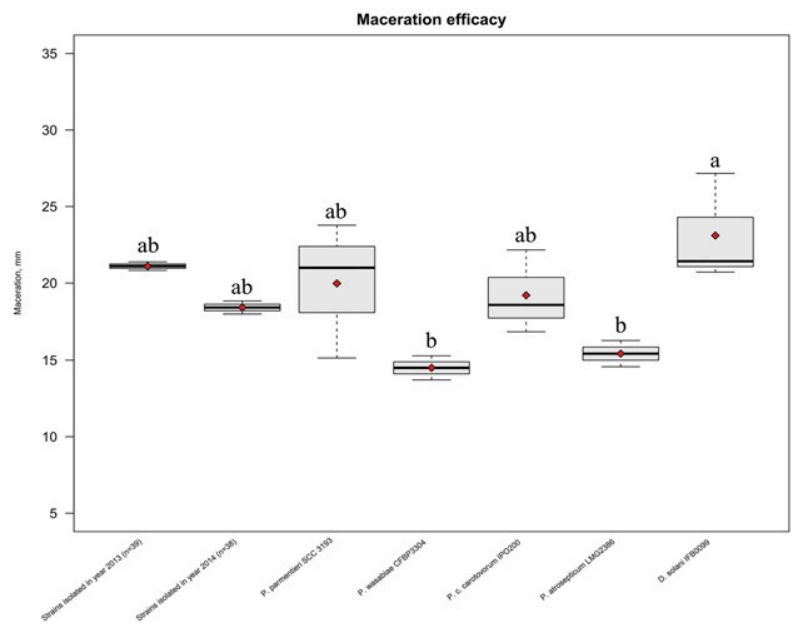

Fig. 5. Comparison of the potato tissue maceration ability of the tested Pectobacterium and Dickeya strains. The top and bottom lines of the boxplot refer to upper and lower quartiles, respectively. The ends of the whiskers reach minimum and maximum values. The dark diamond represents the mean and the black bar depicts the median. Outliners are marked by circles.
To the best of our knowledge, this is the first study focusing on extensive investigation of two $P$. parmentieri populations that originated from consecutive growing seasons under temperate climate conditions. High heterogeneity within this newly established species was proven on the basis of genotypic and phenotypic characterization of upper and lower $78 \mathrm{P}$. parmentieri strains isolated from potato fields. Because the implemented control measures for potato soft rot and blackleg involve only preventive methods, performing monitoring studies in addition to broadening knowledge on biodiversity of $P$. parmentieri now seems crucial.

\section{Acknowledgments}

This work was supported by the National Science Centre in Poland via grant number 2014/14/M/NZ8/00501 awarded to E. Lojkowska.

\section{Literature Cited}

Adeolu, M., Seema, A., Naushad, S., and Gupta, R. S. 2016. Genome-based phylogeny and taxonomy of the "Enterobacteriales": Proposal for Enterobacterales ord. nov. divided into the families Enterobacteriaceae, Erwiniaceae fam. nov., Pectobacteriaceae fam. nov., Yersiniaceae fam. nov., Hafniaceae fam. nov., Morganellaceae fam. nov., and Budviciaceae fam. nov. Int. J. Syst. Evol. Microbiol. 66:5575-5599. 
Central Statistical Office of Poland. 2016. Statistical Year Book of Agriculture, 2016. Warsaw, Poland

Charkowski, A., Blanco, C., Condemine, G., Expert, D., Franza, T., Hayes, C., et al. 2012. The Role of Secretion Systems and Small Molecules in Soft-Rot Enterobacteriaceae Pathogenicity. Annu. Rev. Phytopathol. 50:425-449.

Chatterjee, A., Cui, Y., Liu, Y., Dumenyo, C. K., and Chatterjee, A. K. 1995. Inactivation of rsmA leads to overproduction of extracellular pectinases, cellulases, and proteases in Erwinia carotovora subsp. carotovora in the absence of the starvation/cell density-sensing signal, N-(3-oxohexanoyl)-Lhomoserine lactone. Appl. Environ. Microbiol. 61:1959-67.

De Boer, S. H., Li, X., and Ward, L. J. 2012. Pectobacterium spp. associated with bacterial stem rot syndrome of potato in Canada. Phytopathology 102: 937-947.

Dees, M. W., Lebecka, R., Perminow, J. I. S., Czajkowski, R., Grupa, A., Motyka, A., Zoledowska, S., Sliwka, J., Lojkowska, E., and Brurberg, M. B. 2017. Characterization of Dickeya and Pectobacterium strains obtained from diseased potato plants in different climatic conditions of Norway and Poland. Eur. J. Plant Pathol. 148:839-851.

de Haan, E. G., Dekker-Nooren, T. C. E. M., van den Bovenkamp, G. W., Speksnijder, A. G. C. L., van der Zouwen, P. S., and van der Wolf, J. M. 2008. Pectobacterium carotovorum subsp. carotovorum can cause potato blackleg in temperate climates. Eur. J. Plant Pathol. 122:561-569.

Dung, J. K. S., Johnson, D. A., and Schroeder, B. K. 2012. First report of Pectobacterium wasabiae causing aerial stem rot of potato in Washington State. Plant Dis. 96:1819.

Eriksson, A. R. B., Andersson, R. A., Pirhonen, M., and Palva, E. T. 1998. TwoComponent regulators involved in the global control of virulence in Erwinia carotovora subsp. carotovora. Mol. Plant-Microbe Interact. 11:743-752.

Excoffier, L., Laval, G., and Schneider, S. 2005. Arlequin (version 3.0): An integrated software package for population genetics data analysis. Evol. Bioinf. Online 1:47-50.

Gardan, L., Gouy, C., Christen, R., and Samson, R. 2003. Elevation of three subspecies of Pectobacterium carotovorum to species level: Pectobacterium atrosepticum $\mathrm{sp}$. nov., Pectobacterium betavasculorum sp. nov. and Pectobacterium wasabiae sp. nov. Int. J. Syst. Evol. Microbiol. 53:381-391.

Golanowska, M., Kielar, J., and Lojkowska, E. 2016. The effect of temperature on the phenotypic features and the maceration ability of Dickeya solani strains isolated in Finland, Israel and Poland. Eur. J. Plant Pathol. 147:1-15.

Goto, M., and Matsumoto, K. 1987. Erwinia carotovora subsp. wasabiae subsp. nov. isolated from diseased rhizomes and fibrous roots of Japanese Horseradish (Eutrema wasabi Maxim.). Int. J. Syst. Bacteriol. 37:130-135.

Harshey, R. M. 2003. Bacterial motility on a surface: Many ways to a common goal. Annu. Rev. Microbiol. 57:249-273.

Hauben, L., Moore, E. R. B., Vauterin, L., Steenackers, M., Mergaert, J., Verdonck, L., and Swings, J. 1998. Phylogenetic position of phytopathogens within the Enterobacteriaceae. Syst. Appl. Microbiol. 21:384-397.

Hugouvieux-Cotte-Pattat, N., Condemine, G., Nasser, W., and Reverchon, S. 1996. Regulation of pectinolysis in Erwinia chrysanthemi. Annu. Rev. Microbiol. 50:213-257.

Hyman, L. J., Sullivan, L., Toth, I. K., and Perombelon, M. C. M. 2001. Modified crystal violet pectate medium (CVP) based on a new polypectate source (Slendid) for the detection and isolation of soft rot erwinias. Potato Res. 44: 265-270.

Ishimaru, C. A., and Loper, J. E. 1992. High-affinity iron uptake systems present in Erwinia carotovora subsp. carotovora include the hydroxamate siderophore aerobactin. J. Bacteriol. 174:2993-3003.

Ji, J., Hugouvieux-Cotte-Pattat, N., and Robert-Baudoy, J. 1987. Use of Mu-lac insertions to study the secretion of pectate lyases by Erwinia chrysanthemi. Microbiology 133:793-802.

Kang, H. W., Kwon, S. W., and Go, S. J. 2003. PCR-based specific and sensitive detection of Pectobacterium carotovorum spp. carotovorum by primers generated from a URP-PCR fingerprinting-derived polymorphic band. Plant Pathol. 52:127-133.

Khayi, S., Cigna, J., Chong, T. M., Quêtu-Laurent, A., Chan, K.-G., Hélias, V., and Faure, D. 2016. Transfer of the potato plant isolates of Pectobacterium wasabiae to Pectobacterium parmentieri sp. nov. Int. J. Syst. Evol. Microbiol. 66: 5379-5383.

Koskinen, J. P., Laine, P., Niemi, O., Nykyri, J., Harjunpää, H., Auvinen, P., Paulin, L., Pirhonen, M., Palva, T., and Holm, L. 2012. Genome sequence of Pectobacterium sp. strain SCC3193. J. Bacteriol. 194:6004.

Leong, S. A., and Neilands, J. B. 1982. Siderophore production by phytopathogenic microbial species. Arch. Biochem. Biophys. 218:351-359.

Liu, Y., Jiang, G., Cui, Y., Mukherjee, A., Ma, W. L., and Chatterjee, A. K. 1999. kdgREcc negatively regulates genes for pectinases, cellulase, protease, HarpinEcc, and a global RNA regulator in Erwinia carotovora subsp. carotovora. J. Bacteriol. 181:2411-21.

Ma, B., Hibbing, M. E., Kim, H.-S., Reedy, R. M., Yedidia, I., Breuer, J. J. J., Glasner, J. D., Perna, N. T., Kelman, A., and Charkowski, A. O. 2007. Host range and molecular phylogenies of the soft rot enterobacterial genera Pectobacterium and Dickeya. Phytopathology 97:1150-1163.

Mäki-Valkama, T., and Karjalainen, R. 1994. Differentiation of Erwinia carotovora subsp. atroseptica and carotovora by RAPD-PCR. Ann. Appl. Biol. 125: 301-309.
Mansfield, J., Genin, S., Magor, S., Citovsky, V., Sriariyanum, M., Ronald, P., Dow, M., Verdier, V., Beer, S. V., Machado, M. A., Toth, I., Salmnd, G., and Foster, G. D. 2012. Top 10 plant pathogenic bacteria in molecular plant pathology. Mol. Plant Pathol. 13:614-629.

Marits, R., Koiv, V., Laasik, E., and Mae, A. 1999. Isolation of an extracellular protease gene of Erwinia carotovora subsp. carotovora strain SCC3193 by transposon mutagenesis and the role of protease in phytopathogenicity. Microbiology 145:1959-1966.

Mengoni, A., and Bazzicalupo, M. 2002. The statistical treatment of data and the Analysis of MOlecular VAriance (AMOVA) in molecular microbial ecology. Ann. Microbiol. 52:95-101.

Moleleki, L. N., Onkendi, E. M., Mongae, A., and Kubheka, G. C. 2013 Characterisation of Pectobacterium wasabiae causing blackleg and soft rot diseases in South Africa. Eur. J. Plant Pathol. 135:279-288.

Nabhan, S., Wydra, K., Linde, M., and Debener, T. 2012. The use of two complementary DNA assays, AFLP and MLSA, for epidemic and phylogenetic studies of pectolytic enterobacterial strains with focus on the heterogeneous species Pectobacterium carotovorum. Plant Pathol. 61:498-508.

Naeem, S., and Li, S. 1997. Biodiversity enhances ecosystem reliability. Nature 390:507-509.

Nykyri, J., Niemi, O., Koskinen, P., Nokso-Koivisto, J., Pasanen, M., Broberg, M., Plyusnin, I., Törönen, P., Holm, L., Pirhonen, M., and Palva, E. T. 2012. Revised phylogeny and novel horizontally acquired virulence determinants of the model soft rot phytopathogen Pectobacterium wasabiae SCC3193. PLoS Pathog 8:e1003013.

Pasanen, M., Laurila, J., Brader, G., Palva, E. T. T., Ahola, V., Van Der Wolf, J., Hannukkala, A., and Pirhonen, M. 2013. Characterisation of Pectobacterium wasabiae and Pectobacterium carotovorum subsp. carotovorum isolates from diseased potato plants in Finland. Ann. Appl. Biol. 163:403-419.

Pickersgill, R., Smith, D., Worboys, K., and Jenkins, J. 1998. Crystal structure of polygalacturonase from Erwinia carotovora subsp. carotovora. J. Biol. Chem. 273:24660-24664

Pitman, A. R., Harrow, S. A., and Visnovsky, S. B. 2010. Genetic characterisation of Pectobacterium wasabiae causing soft rot disease of potato in New Zealand. Eur. J. Plant Pathol. 126:423-435.

Potrykus, M., Golanowska, M., Hugouvieux-Cotte-Pattat, N., and Lojkowska E. 2014a. Regulators involved in Dickeya solani virulence, genetic conservation, and functional variability. Mol. Plant-Microbe Interact. 27: 700-711.

Potrykus, M., Golanowska, M., Sledz, W., Zoledowska, S., Motyka, A., Kolodziejska, A., Butrymowicz, J., and Lojkowska, E. 2016. Biodiversity of Dickeya spp. isolated from potato plants and water sources in temperate climate. Plant Dis. 100:408-417.

Potrykus, M., Sledz, W., Golanowska, M., Slawiak, M., Binek, A., Motyka A., Zoledowska, S., Czajkowski, R., and Lojkowska, E. 2014b. Simultaneous detection of major blackleg and soft rot bacterial pathogens in potato by multiplex polymerase chain reaction. Ann. Appl. Biol. 165: 474-487.

Py, B., Salmond, G. P. C., Chippaux, M., and Barras, F. 1991. Secretion of cellulases in Erwinia chrysanthemi and E. carotovora in species-specific. FEMS Microbiol. Lett. 79:315-322.

R Core Team. (2016). R: A language and environment for statistical computing. R Foundation for Statistical Computing, Vienna, Austria. URL https://www. R-project.org/

Reverchon, S., Van Gijsegem, F., Rouve, M., Kotoujansky, A., and Robert-Baudouy, J. 1986. Organization of a pectate lyase gene family in Erwinia chrysanthemi. Gene 49:215-224

Rosenzweig, N., Steere, L., Kirk, W. W., Mambetova, S., Long, C., Schafer, R., Dangi, S., and Byrne, J. 2016. First report of Dickeya dianthicola and Pectobacterium wasabiae causing aerial stem rot of potato in Michigan, USA. New Dis. Rep. 33:10.

Schwyn, B., and Neilands, J. B. 1987. Universal chemical assay for the detection and determination of siderophores. Anal. Biochem. 160:47-56.

Sławiak, M., van Beckhoven, J. R. C. M., Speksnijder, A. G. C. L., Czajkowski, R., Grabe, G., and van der Wolf, J. M. 2009. Biochemical and genetical analysis reveal a new clade of biovar 3 Dickeya spp. strains isolated from potato in Europe. Eur. J. Plant Pathol. 125:245-261.

Sławiak, M., van Doorn, R., Szemes, M., Speksnijder, A. G. C. L., Waleron, M., van der Wolf, J. M., Lojkowska, E., and Schoen, C. D. 2013. Multiplex detection and identification of bacterial pathogens causing potato blackleg and soft rot in Europe, using padlock probes. Ann. Appl. Biol. 163:378-393.

Suárez, M. B., Feria, F. J., Martín-Robles, M. J., del Rey, F. J., and Palomo, J. L. 2017. Pectobacterium parmentieri causing soft rot on potato tubers in southern Europe. Plant Dis. 101:1029.

Toth, I. K., Bell, K. S., Holeva, M. C., and Birch, P. R. J. 2003. Soft rot Erwiniae From genes to genomes. Mol. Plant Pathol. 4:17-30.

Versalovic, J., Koeuth, T., and Lupski, R. 1991. Distribution of repetitive DNA sequences in eubacteria and application to fingerprinting of bacterial genomes. Nucleic Acids Res. 19:6823-6831.

Waleron, K., Waleron, M., Podhajska, A. J., and Lojkowska, E. 2002. Genotyping of bacteria belonging to the former Erwinia genus by PCR-RFLP analysis of a recA gene fragment. Microbiology 148:583-595. 
Waleron, M., Waleron, K., and Lojkowska, E. 2013. Occurrence of Pectobacterium wasabiae in potato field samples. Eur. J. Plant Pathol. 137:149-158.

Wang, J., Pan, F., Soininen, J., Heino, J., and Shen, J. 2016. Nutrient enrichment modifies temperature-biodiversity relationships in large-scale field experiments. Nat. Commun. 7: Article 13960. 10.1038/ncomms13960

Wood, P. J. 1980. Specificity in the interaction of direct dyes with polysaccharides. Carbohydr. Res. 85:271-287.
Yap, M.-N., Barak, J. D., and Charkowski, A. O. 2004. Genomic diversity of Erwinia carotovora subsp. carotovora and its correlation with virulence. Appl. Environ. Microbiol. 70:3013-3023.

Yishay, M., Burdman, S., Valverde, A., Luzzatto, T., Ophir, R., and Yedidia, I. 2008. Differential pathogenicity and genetic diversity among Pectobacterium carotovorum ssp. carotovorum isolates from monocot and dicot hosts support early genomic divergence within this taxon. Environ. Microbiol. 10:2746-2759. 